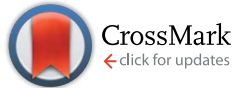

Cite this: RSC Adv., 2015, 5, 37119

Received 25th February 2015 Accepted 13th April 2015

DOI: $10.1039 / \mathrm{c} 5 \mathrm{ra0} 3438 \mathrm{~h}$

www.rsc.org/advances

\section{Unravelling the mechanism of the ketene-imine Staudinger reaction. An ELF quantum topological analysis $\uparrow$}

\author{
Luis R. Domingo,* Mar Ríos-Gutiérrez and José A. Sáez
}

The mechanism of the ketene-imine Staudinger ( $\mathrm{KI}-\mathrm{S}$ ) reaction between $t$-butyl-cyano ketene and $N$-phenyl phenylimine has been studied using DFT methods at the MPWB1K/6-311G(d) computational level. The reaction takes place through a two-step mechanism: (i) the first step is the nucleophilic attack of the imine nitrogen lone pair on the central carbon of the ketene yielding a zwitterionic (ZW) intermediate; (ii) the second step, which is the rate- and stereoselectivity-determining step, is a ringclosure process achieved by a nucleophilic attack of the terminal carbon atom of the ketene on the imine carbon atom. Due to the unfeasibility of a cis/trans and an E/Z stereoisomerisation at the ZW intermediates, trans and cis $\beta$-lactams are formed along the endo and exo stereoisomeric channels, respectively. An electron localisation function (ELF) quantum topological analysis of the bonding changes along the KI-S reaction permits a complete characterisation of the mechanism. The first step is associated with the formation of the $\mathrm{N} 1-\mathrm{C} 4$ single bond along the nucleophilic attack of the imine nitrogen lone pair on the central carbon of the ketene, while the second step is associated with a ringclosure process achieved by the C-to-C coupling of the $\mathrm{C} 2$ and $\mathrm{C} 3$ pseudoradical centers generated in the previous phases. The present theoretical study makes it possible to reject those analyses based on the FMO theory, in which HOMO/LUMO interactions along the nucleophilic attack of the imines on the ketenes and a feasible torquoelectronic effect along the conrotatory ring-closure step control the cis/trans stereoselectivity in the formation of $\beta$-lactams.

\section{Introduction}

The $\beta$-lactam skeleton is the key structural element of the most widely employed family of antimicrobial agents to date, $\beta$-lactam antibiotics. ${ }^{1}$ The first classical synthesis of molecules containing the $\beta$-lactam skeleton was the ketene-imine Staudinger

Departamento de Química Orgánica, Universidad de Valencia, Dr Moliner 50, E-46100 Burjassot, Valencia, Spain. E-mail: domingo@utopia.uv.es; Web: http://www. luisrdomingo.com

$\dagger$ Electronic supplementary information (ESI) available: ELF topological analysis of bonding changes along the KI-S reaction between MCK 18 and $N$-methyl imine 19, and of the stationary points involved in the endo stereoisomeric path of the KI-S reaction of TBCK 11 with $N$-phenyl imine 12a. MPWB1K/6-311G(d) gas phase total and relative energies, total energies in benzene, and enthalpies, entropies and Gibbs free energies, computed at $80^{\circ} \mathrm{C}$ and $1 \mathrm{~atm}$ in benzene, of the stationary structures involved in the reaction of TBCK 11 with $N$-phenyl imine 12a. M062X/6-311G(d) Gibbs free energies and the relative ones, computed at $80{ }^{\circ} \mathrm{C}$ and 1 atm in benzene, of the most relevant stationary structures involved in the reaction of TBCK $\mathbf{1 1}$ with $N$-phenyl imine 12a. MPWB1K/6-311G(d) total and relative energies, in benzene, of the stationary points along the endo and exo stereoisomeric channels associated with the KI-S reactions of $N$-phenyl imine 12a with the monosubtituted ketenes 15a-c. MPWB1K/6-311G(d) gas phase total and relative energies of the stationary structures involved in the reaction of MCK 18 with $N$-methyl imine 19. Cartesian coordinates of all species involved in the studied KI-S reactions. See DOI: $10.1039 / \mathrm{c} 5 \mathrm{ra} 03438 \mathrm{~h}$
(KI-S) reaction, ${ }^{2}$ which is a formal $[2+2]$ cycloaddition between a ketene 1 and an imine 2 yielding a $\beta$-lactam 4 (Scheme 1). ${ }^{3,4}$

A plethora of theoretical studies has been devoted to establish the mechanism of the KI-S reaction, as well as the stereoselectivity in the cyclisation step. ${ }^{\mathbf{4} 5}$ Originally, the KI-S reaction was classified as a pericyclic reaction. However, since $[2+2]$ cycloadditions are forbidden and zwitterionic (ZW) intermediates were experimentally characterised, the pericyclic mechanism was quickly rejected. The accepted mechanism of the KI-S reaction is shown in Scheme 1 . The reaction begins with the nucleophilic attack of imine 2 on the carbonyl carbon of ketene 1 to yield ZW intermediate 3 . The subsequent ring closure at this intermediate yields $\beta$-lactam 4 . This step has been associated with an electrocyclic reaction; ${ }^{\mathbf{4}, 5 \boldsymbol{a}, \boldsymbol{d}}$ consequently, a conrotatory electrocyclisation process at ZW intermediate 3 has

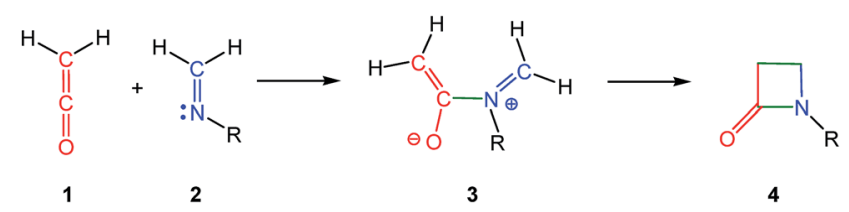

Scheme 1 Mechanism of the KI-S reaction. 
been proposed along the formation of $\beta$-lactams. The frontier molecular orbital (FMO) theory has been intensively used in order to explain both the mechanism and cis/trans stereoselectivity in KI-S reactions.

The reaction of unsymmetrical substituted ketenes and imines may form cis and trans $\beta$-lactams (see Scheme 2 ). ${ }^{6}$ If only steric effects are considered, the preferred reactive channel is that in which the bulky substituent R1 of the ketene is located outward from the imine nitrogen atom, leading to exo $\mathrm{ZW}$ intermediates. Houk proposed that along the conrotatory electrocyclic reactions of butadienes torquoelectronic effects are responsible for the inward or outward movements. ${ }^{7}$ Cossio suggested that the strong analogy observed in the torquoselectivity of KI-S reactions compared with the conrotatory electrocyclic reactions of butadienes supports the pericyclic reactivity of the ZW intermediates formed in the KI-S reaction. ${ }^{4}$ Consequently, it has been assumed that from $(E)$-imines, cis $\beta$-lactams are usually expected.

The analysis of the electron density reorganisation to evidence the bonding changes along a reaction path is the most attractive method to characterise a reaction mechanism. ${ }^{8}$ An appealing procedure that provides a straightforward connection between the electron density distribution and the chemical structure is the study of the quantum chemical topology of the electron density based on the electron localisation function (ELF) of Becke and Edgecombe. ${ }^{9}$ In this sense, Silvi and Savin presented the ELF in a very chemical fashion, using their topological analysis as a chemical bonding model. ${ }^{\mathbf{1 0}}$

An ELF quantum topological analysis along the intrinsic reaction coordinate ${ }^{\mathbf{1 1}}$ (IRC) curve associated with the ringaperture of cyclobutene 5 yielding 1,3-butadiene 6 has revealed that the bonding changes along the one-step mechanism take place along five different phases, the electrocyclic reaction being non-concerted (see Scheme 3 ). ${ }^{8 b}$ This behaviour allows rejecting the proposed pericyclic mechanism ${ }^{\mathbf{1 2}}$ for this electrocyclic reaction. ${ }^{13}$ In addition, as the reaction begins with the rupture of the $\mathrm{C}-\mathrm{C}$ single bond, the analysis based on the symmetry of the $\mathrm{p}_{\mathrm{z}}$ atomic orbital of butadiene should be rejected when explaining the conrotatory aperture. ${ }^{\mathbf{1 4}}$

The selectivity in the formation of $\beta$ - $v s$. $\delta$-lactams in the KI-S reaction between chloro-cyano-ketene (CCK, 7) and two phenyl substituted unsaturated imines $\mathbf{8 a}, \mathbf{b}$ has been studied very recently (see Scheme 4). ${ }^{15}$ These reactions are initialised by the

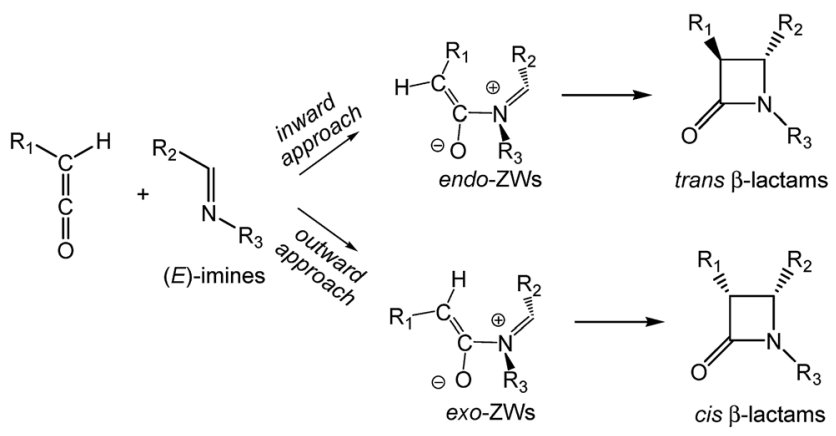

Scheme 2 Formation of cis and trans $\beta$-lactams in $\mathrm{KI}-\mathrm{S}$ reactions.

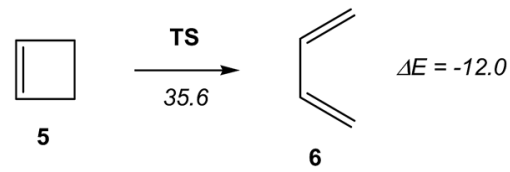

Scheme 3 Electrocyclic aperture of cyclobutene 5. Energies are in kcal mol ${ }^{-1}$

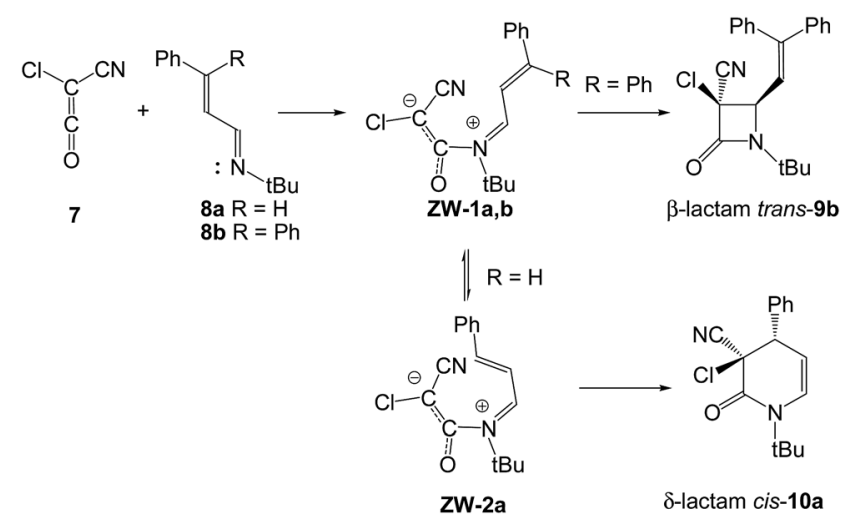

Scheme $4 \mathrm{KI}-\mathrm{S}$ reactions between CCK 7 and the unsaturated imines $8 a, b$.

nucleophilic attack of unsaturated imines $\mathbf{8 a}, \mathbf{b}$ on ketene 7 with formation of $\mathrm{ZW}$ intermediates $\mathbf{Z W}-\mathbf{1 a}, \mathbf{b}$. The subsequent $\mathrm{C}-\mathrm{C}$ single bond formation at the imine carbon or at the $\beta$-conjugated position enables the formation of $\beta$ - or $\delta$-lactams trans-9b or cis-10a, respectively. Due to the high electrophilic character of CCK 7, $\omega=2.20 \mathrm{eV},{ }^{16}$ and the high nucleophilic character of these unsaturated imines, $N=3.61 \mathrm{eV}(\mathbf{8 a})$ and $3.74 \mathrm{eV}(\mathbf{8 b}),{ }^{17}$ the nucleophilic attack did not present any activation barrier. Analysis of the energies involved in the two competitive channels associated with the ring-closure processes explained the selectivity experimentally observed; in the absence of any steric hindrance, formation of $\delta$-lactam cis-10a is favoured over the formation of the corresponding $\beta$-lactam.

In addition, due to the structural behaviours of the $\mathrm{ZW}$ intermediates, in which the ketene and imine frameworks present a quasi perpendicular rearrangement, no specific rotation for the subsequent $\mathrm{C}-\mathrm{C}$ single bond formation is required. ${ }^{15}$ Consequently, formation of $\beta$-lactam trans-9b is determined by the endo approach mode of the cyano substituent of CCK 7 with respect to the nitrogen atom of the corresponding unsaturated imine $\mathbf{8 b}$. Therefore, no torquoelectronic processes take place in these KI-S reactions, as has been proposed. ${ }^{4}$

An ELF topological analysis of the bonding changes along the cyclisation step allowed establishing that the formation of the second $\mathrm{C}-\mathrm{C}$ bond takes place through a retro-donation process involving the nucleophilically activated $\mathrm{C}-\mathrm{C}$ double bond of the ketene and the electrophilically activated $\mathrm{C}-\mathrm{N}$ or $\mathrm{C}-\mathrm{C}$ double bond of the unsaturated imines. Thus, since the $\mathrm{N}-\mathrm{C}$ single bond formed along the first step of the KI-S reaction does not participate in the cyclisation step, the electrocyclic mechanism was ruled out. ${ }^{15}$ 

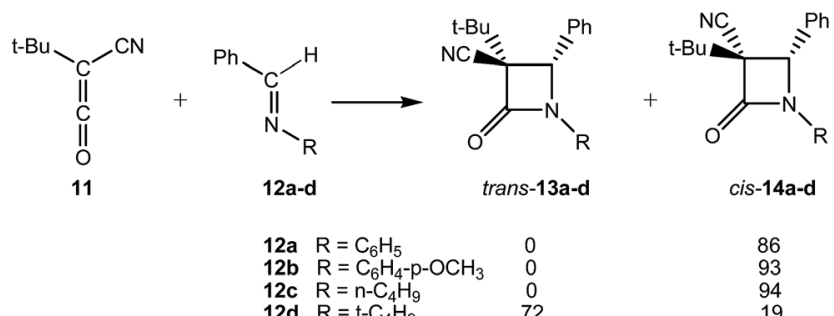

cis-14a-d

12b $\mathrm{R}=\mathrm{C}_{6} \mathrm{H}_{4}-\mathrm{p}-\mathrm{O}$

12d $\mathrm{R}=\mathrm{t}-\mathrm{C}_{4} \mathrm{H}_{9}$

0
0
0
72

86
93
94
19

Scheme $5 \mathrm{KI}-\mathrm{S}$ reactions between TBCK 11 and $\mathrm{N}$-substituted imines $12 \mathrm{a}-\mathrm{d}$.

The KI-S reactions between $t$-butyl-cyano-ketene (TBCK, 11) and $\mathrm{N}$-substituted imines 12a-d yielding the corresponding $\beta$-lactams trans-13a-d and/or cis-14a-d were experimentally studied by Moore (see Scheme 5). ${ }^{18}$ The cis/trans stereoselectivity of these KI-S reactions was directly related to the steric bulk of the N-substituent of the imine. Generally, as this substituent increases in size, the yield of the resulting $\beta$-lactams having a cis relationship between the 3-cyano and 4-protio groups increases. ${ }^{18}$

For the KI-S reactions of TBCK 11 with N-substituted $(E)$-imines 12a,d, Moore proposed that $\beta$-lactams cis-14a and trans-13d are formed through a conrotatory ring-closure in $\mathrm{ZW}$ intermediates $(Z)-\mathbf{Z W}-3 \mathbf{a}$ and $(E)-\mathbf{Z W}$-3d (see Scheme 6). ${ }^{18}$ These ZW intermediates are those in which steric interactions have been minimized, i.e. the smaller CN substituent of TBCK 11 is endo oriented and the larger $t$-Bu one is exo oriented. He proposed that the relative proportions of the $(E)$ and $(Z) \mathrm{ZW}$

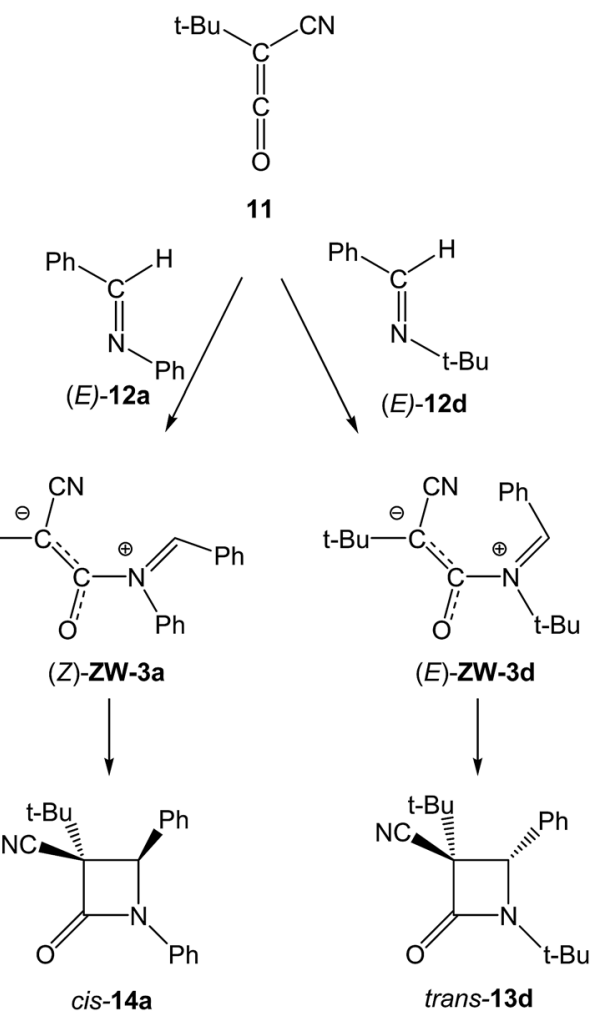

Scheme 6 Proposed origin of the cis/trans stereoselectivity in the KI-S reactions between TBCK 11 and $\mathrm{N}$-substituted imines $12 \mathrm{a}, \mathrm{d} .{ }^{18}$ intermediates, and thus also the corresponding $\beta$-lactams trans13d and cis-14a, are significantly influenced by the bulk of the $\mathrm{N}$-substituent. That is, when $\mathrm{R}$ is a small phenyl group, (Z)-ZW-3a is greatly favoured since the phenyl/cyano interaction is relieved, and thus $\beta$-lactams cis-14a results as the major or exclusive product. However, when $\mathrm{R}$ becomes a larger $t$-butyl group its steric interaction with the adjacent phenyl group increases, and thus the concentration of $(E)-\mathbf{Z W}$-3d also increases. ${ }^{18}$ Note that an $E / Z$ isomerisation at the expected $(E)-\mathbf{Z W}-\mathbf{3 a}$ is demanded in this mechanism for the formation of $\beta$-lactam cis-14a.

Herein, the KI-S reaction between TBCK 11 and $N$-phenyl imine 12a, experimentally studied by Moore, ${ }^{18}$ yielding $\beta$-lactams trans-13a and/or cis-14a is investigated using DFT methods at the MPWB1K/6-311G(d) level in benzene (see Scheme 5). The aim of this theoretical study is to perform a complete characterisation of the molecular mechanism of the KI-S reaction. For this purpose, an ELF topological analysis of the bonding changes along the endo reactive channel associated with the KI$\mathrm{S}$ reaction between methyl-cyano-ketene (MCK, 18) and $\mathrm{N}$ methyl imine 19, as a reduced model of the KI-S reaction between TBCK 11 and imine 12a, is carried out. In addition, the factors controlling the endo/exo selectivity are analysed.

\section{Computational methods}

DFT computations were carried out using the MPWB1K ${ }^{19}$ exchange-correlation functional, together with the standard 6-311G(d) basis set. ${ }^{20}$ The optimisations were performed using the Berny analytical gradient optimisation method. ${ }^{21}$ The stationary points were characterised by frequency computations in order to verify that TSs have one and only one imaginary frequency. The IRC paths ${ }^{\mathbf{1 1}}$ were traced in order to check the energy profiles connecting each TS to the two associated minima of the proposed mechanism using the second order González-Schlegel integration method. ${ }^{22}$ Solvent effects of benzene in the optimisations were taken into account using the polarisable continuum model (PCM) as developed by Tomasi's group $^{23}$ in the framework of the self-consistent reaction field (SCRF). ${ }^{24}$ Values of enthalpies, entropies and free energies in benzene were calculated with the standard statistical thermodynamics at $80{ }^{\circ} \mathrm{C}$ and 1 atm..$^{20}$ The electronic structures of the stationary points were analysed by the natural bond orbital (NBO) method $^{25}$ and by the ELF topological analysis, $\eta(\mathbf{r}){ }^{9}$ The ELF study was performed with the TopMod program ${ }^{26}$ using the corresponding monodeterminantal wavefunctions of the selected structures of the IRC. All computations were carried out with the Gaussian 09 suite of programs. ${ }^{27}$

The global electrophilicity index, ${ }^{\mathbf{1 6}} \omega$, is given by the following expression, $\omega=\left(\mu^{2} / 2 \eta\right)$, in terms of the electronic chemical potential $\mu$ and the chemical hardness $\eta$. Both quantities may be approached in terms of the one-electron energies of the frontier molecular orbitals HOMO and LUMO, $\varepsilon_{\mathrm{H}}$ and $\varepsilon_{\mathrm{L}}$, as $\mu \approx\left(\varepsilon_{\mathrm{H}}+\varepsilon_{\mathrm{L}}\right) / 2$ and $\eta \approx\left(\varepsilon_{\mathrm{L}}-\varepsilon_{\mathrm{H}}\right)$, respectively. ${ }^{28}$ The global nucleophilicity index, ${ }^{17} N$, based on the HOMO energies obtained within the Kohn-Sham scheme, ${ }^{29}$ is defined as $N=$ $E_{\text {номо }}(\mathrm{Nu})-E_{\text {Номо }}(\mathrm{TCE})$. This relative nucleophilicity index is referred to tetracyanoethylene (TCE). 


\section{Results and discussion}

The present theoretical study has been divided into three parts: (i) first, energetic and geometrical details of the KI-S reaction between TBCK 11 and $N$-phenyl imine 12a yielding $\beta$-lactams trans-13a and/or cis-14a are given; (ii) then, the origin of the cis/ trans stereoselectivity in the KI-S reaction is analysed; finally (iii) an ELF topological analysis of the reaction between MCK 18 and $\mathrm{N}$-methyl imine $\mathbf{1 9}$ is carried out in order to characterise the molecular mechanism of the KI-S reaction.

\section{(i) Energy and geometry details of the KI-S reaction between} TBCK 11 and $N$-phenyl imine 12a

Due to the unsymmetry of TBCK 11 and $N$-phenyl imine 12a, two stereoisomeric approach modes, the endo and the exo ones, are feasible along the nucleophilic attack of imine 12a on ketene $\mathbf{1 1 .}$ They are related to the two stereoisomeric approach modes of the cyano group of TBCK 11 relative to the $\mathrm{sp}^{2}$ hybridised N1 nitrogen of imine 12a; along the endo channel, the cyano group is placed over the nitrogen atom of the imine framework. An exploration of the potential energy surface (PES) for this polar reaction allowed finding two TSs and one $\mathrm{ZW}$ intermediate along each stereoisomeric channel connecting both TSs, indicating that this reaction takes place through a two-step mechanism. Consequently, the reagents, two TSs, one ZW intermediate and the corresponding $\beta$-lactam were located and characterised along each stereoisomeric channel (see Scheme 7). Relative energies in benzene of the stationary points associated with this KI-S reaction are given in Table 1, while the total electronic energies are given in Table S4 in the ESI. $\dagger$ Gas phase electronic energies are given in Table S3 in the ESI. $\dagger$

The activation energies associated with the nucleophilic attack of the N1 nitrogen of $N$-phenyl imine 12a on the C4 carbon of TBCK 11 in benzene are 2.2 (TS1-4n) and 13.8 (TS1-4x) kcal $\mathrm{mol}^{-1}$; formation of the $\mathrm{ZW}$ intermediate resulting from the endo approach mode, $\mathbf{Z W}-\mathbf{4 n}$, is exothermic by

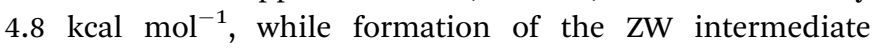
resulting from the exo one, $\mathbf{Z W}-\mathbf{4 x}$, is endothermic by $4.5 \mathrm{kcal}$ $\mathrm{mol}^{-1}$. The activation energy associated with the C3-C4 and N1-C2 bond rotations at ZW-4n has been estimated to be $c a .32$
Table 1 MPW1K/6-311G(d) relative ${ }^{a}$ electronic energies $(\Delta E$, in kcal $\left.\mathrm{mol}^{-1}\right)$ in benzene, and enthalpies $\left(\Delta H\right.$, in $\left.\mathrm{kcal} \mathrm{mol}^{-1}\right)$, entropies $(\Delta S$, in cal mol $\mathrm{m}^{-1} \mathrm{~K}^{-1}$ ) and Gibbs free energies $\left(\Delta G\right.$, in $\left.\mathrm{kcal} \mathrm{mol}^{-1}\right)$, computed at $80^{\circ} \mathrm{C}$ and $1 \mathrm{~atm}$ in benzene, of the stationary structures involved in the $\mathrm{KI}-\mathrm{S}$ reaction of TBCK 11 with $\mathrm{N}$-phenyl imine $12 \mathrm{a}$

\begin{tabular}{lrrrr}
\hline & \multicolumn{1}{c}{$\Delta E$} & \multicolumn{1}{c}{$\Delta H$} & \multicolumn{1}{c}{$\Delta S$} & \multicolumn{1}{c}{$\Delta G$} \\
\hline TS1-4n & 2.2 & 3.1 & -43.1 & 18.3 \\
TS1-4x & 13.8 & 14.9 & -43.7 & 30.3 \\
ZW-4n & -4.8 & -2.5 & -46.8 & 14.0 \\
ZW-4x & 4.5 & 6.9 & -51.8 & 25.2 \\
TS2-4n & 11.9 & 13.1 & -53.2 & 31.8 \\
TS2-4x & 20.0 & 21.0 & -52.4 & 39.5 \\
trans-13a & -34.1 & -30.6 & -54.1 & -11.5 \\
cis-14a & -38.0 & -34.8 & -51.2 & -16.8
\end{tabular}

${ }^{a}$ Relative to TBCK 11 and $N$-phenyl imine 12a.

and $34 \mathrm{kcal} \mathrm{mol}^{-1}$. These unfavourable energies prevent the endo/exo and the $E / Z$ isomerisations at $\mathbf{Z W - 4 n}$, respectively. These ZW intermediates undergo a cyclisation process yielding $\beta$-lactams trans-13a and cis-14a with an activation energy of 16.7 (TS2-4n) and 15.5 (TS2-4x) $\mathrm{kcal} \mathrm{mol}^{-1}$. The KI-S reaction is strongly exothermic, between -34 and $-38 \mathrm{kcal} \mathrm{mol}^{-1}$.

Some interesting conclusions can be drawn from these energy results: (i) the nucleophilic attack of $N$-phenyl imine 12a on TBCK 11 is completely endo stereoselective, TS1-4x being 11.6 kcal $\mathrm{mol}^{-1}$ higher in energy than TS1-4n; (ii) while formation of $\mathbf{Z W}-\mathbf{4 n}$ is exothermic by ca. $5 \mathrm{kcal} \mathrm{mol}^{-1}$, formation of $\mathbf{Z W}-\mathbf{4 x}$ is endothermic by ca. $5 \mathrm{kcal} \mathrm{mol}^{-1}$; (iii) the $\mathbf{Z W}-\mathbf{4 n} / \mathbf{Z W}$ $\mathbf{4 x}$ isomerisation via the $\mathrm{C} 3-\mathrm{C} 4$ bond rotation is found to be very unfavourable; (iv) the ring-closure along the exo stereoselective channel is found slightly less energetic than that along the endo one. However, as $\mathbf{Z W}-\mathbf{4 n}$ is located $9.3 \mathrm{kcal} \mathrm{mol}^{-1}$ below $\mathbf{Z W}-\mathbf{4 x}$, TS2-4n is found $8.1 \mathrm{kcal} \mathrm{mol}^{-1}$ below TS2-4x; (v) the formation of $\beta$-lactams trans-13a and cis-14a is strongly exothermic; finally, (vi) the very high energy associated with the N1-C2 bond rotation at ZW-4n allows discarding Moore's proposal for the formation of $\beta$-lactam cis-14a from $(E)$ - $N$-phenyl imine 12a (see Scheme 6). ${ }^{18}$

Relative enthalpies, entropies and Gibbs free energies of the stationary points involved in the KI-S reaction of TBCK 11 with

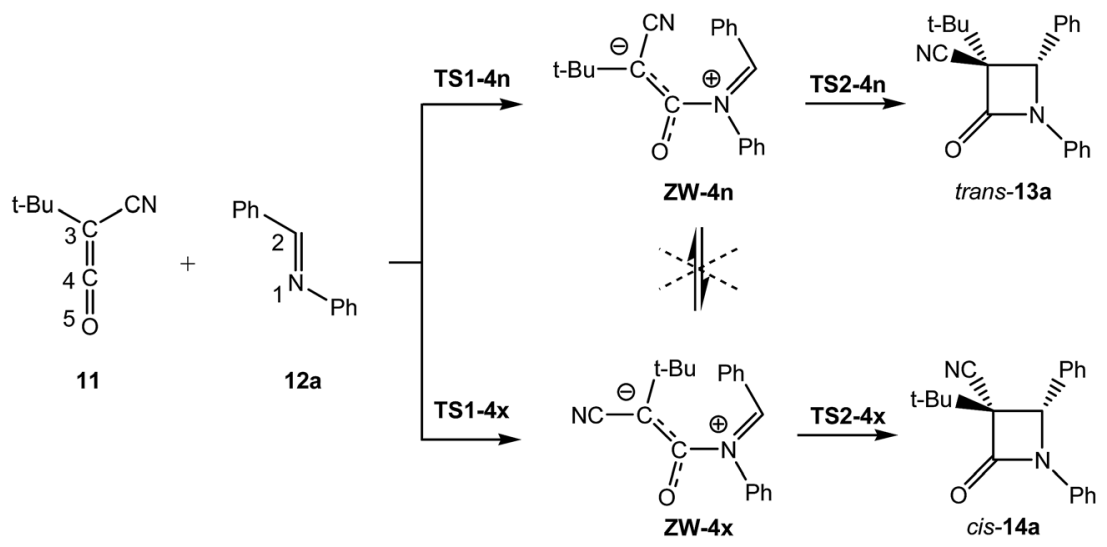

Scheme 7 Mechanism of the KI-S reaction between TBCK 11 and N-phenyl imine 12a. 
$N$-phenyl imine 12a are given in Table 1. Enthalpies, entropies and Gibbs free energies of the stationary points associated with this KI-S reaction are given in Table S4 in the ESI. $\dagger$ The addition of the thermal corrections to the electronic energies increases the activation and reaction enthalpies between 1 and $4 \mathrm{kcal}$ $\mathrm{mol}^{-1}$. The addition of the entropies to enthalpies raises relative Gibbs free energies between 15-19 $\mathrm{kcal} \mathrm{mol}^{-1}$ due to the unfavourable entropy associated with this bimolecular reaction. Thus, the activation Gibbs free energy associated with the nucleophilic attack of $N$-phenyl imine 12a on TBCK 11 increases to 18.3 (TS1-4n) and 30.3 (TS1-4x) $\mathrm{kcal} \mathrm{mol}^{-1}$; formation of ZW intermediates being endergonic by $14.0(\mathbf{Z W}-4 n)$ and 25.2 $(\mathbf{Z W}-\mathbf{4 x}) \mathrm{kcal} \mathrm{mol}^{-1}$. From these $\mathrm{ZW}$ intermediates the activation Gibbs free energy associated with the C2-C3 single bond formation along the ring-closure process is 17.8 (TS2-4n) and 14.3 (TS2-4x) $\mathrm{kcal} \mathrm{mol}^{-1}$. Formation of $\beta$-lactams trans-13a and cis-14a is exergonic by 11.5 and $16.8 \mathrm{kcal} \mathrm{mol}^{-1}$, respectively.

A schematic representation of the Gibbs free energy profile of the two stereoisomeric channels associated with the KI-S reaction of TBCK 11 with $N$-phenyl imine 12a is given in Fig. 1. Some appealing conclusions can be drawn from these Gibbs free energy profiles: (i) due to the endergonic character of the formation of $\mathrm{ZW}$ intermediates $\mathbf{Z W}-\mathbf{4 n}$ and $\mathbf{Z W}-\mathbf{4 x}$, the second step of this stepwise mechanism is the rate- and stereoisomeric-determining step of the reaction; (ii) consequently, the activation Gibbs free energy of this KI-S reaction along the most favourable endo channel is $31.8 \mathrm{kcal} \mathrm{mol}^{-1}$; (iii) the reaction is kinetically endo selective, TS2-4x being $7.7 \mathrm{kcal}$ $\mathrm{mol}^{-1}$ higher in energy than TS2-4n; (iv) $\beta$-lactam cis-14a is 5.3 $\mathrm{kcal} \mathrm{mol}^{-1}$ thermodynamically more stable than $\beta$-lactam trans13a; (v) these data indicate that while $\beta$-lactam trans-13a is the kinetic control product, $\beta$-lactam cis-14a is the thermodynamic control product; and (vi) the activation Gibbs free energy of the retro KI-S reaction from $\beta$-lactam trans-13a, $43.3 \mathrm{kcal} \mathrm{mol}^{-1}$, is slightly higher than that associated with the formation of $\beta$ lactam cis-14a, via TS2-4x, $39.5 \mathrm{kcal} \mathrm{mol}^{-1}$. Therefore, under thermodynamic control, $\beta$-lactam cis-14a becomes the product of this KI-S reaction.

In order to support the MPWB1K energy results for the thermodynamic control in the formation of $\beta$-lactam cis-14a,

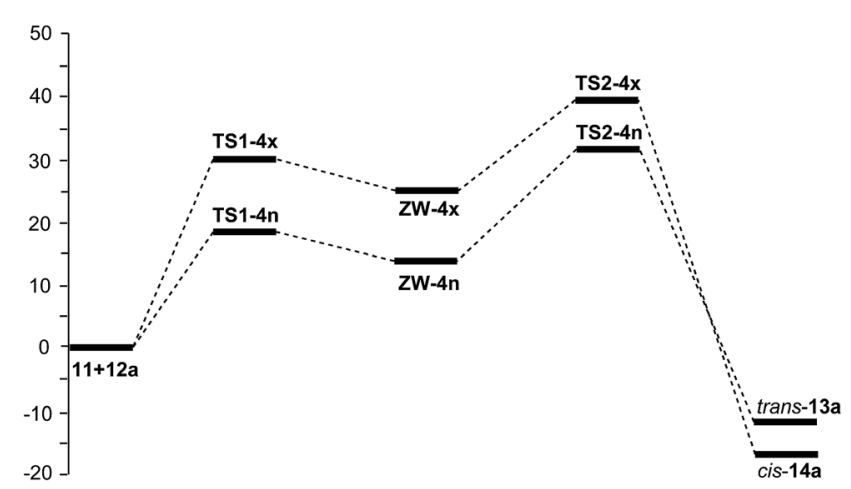

Fig. 1 MPWB1K/6-311G(d) Gibbs free energy profile, in kcal mol ${ }^{-1}$, of the $\mathrm{KI}-\mathrm{S}$ reaction between TBCK 11 and $N$-phenyl imine $12 \mathrm{a}$ in benzene. the Gibbs free energies of the most significant stationary points involved in the formation of the $\beta$-lactams trans-13a and cis-14a were computed using the M062X functional. ${ }^{30}$ Thermodynamic data are given in Table S5 in the ESI. $\dagger$ Analysis of the relative M062X/6-311G(d) Gibbs free energies shows a similar trend to that obtained at the MPWB1K/6-311G(d) level. The activation Gibbs free energy associated with the formation of $\beta$-lactam trans-13a, via TS2-4n, is $29.7 \mathrm{kcal} \mathrm{mol}^{-1}$, formation of trans-13a is exergonic by $12.3 \mathrm{kcal} \mathrm{mol}^{-1}$. $\beta$-Lactam cis-14a is $4.4 \mathrm{kcal}$ $\mathrm{mol}^{-1}$ more stable than $\beta$-lactam trans-13a. Consequently, cis$\mathbf{1 4 a}$ is the product of a thermodynamic control. The activation Gibbs free energy associated with the retro KI-S reaction from trans-13a is $42.0 \mathrm{kcal} \mathrm{mol}^{-1}$, i.e. $4.7 \mathrm{kcal} \mathrm{mol}^{-1}$ higher than the activation Gibbs free energy associated with the formation of $\beta$-lactam cis-14a via TS2-4x. Similar to the MPWB1K results, if the retro KI-S reaction is reached, $\beta$-lactam cis-14a becomes the thermodynamic control product.

The geometries of the TSs involved in the KI-S reaction between TBCK 11 and $N$-phenyl imine 12a are given in Fig. 2. The lengths of the N1-C4 and C2-C3 forming bonds along the nucleophilic attack of imine 12a on TBCK 11 in benzene are 2.124 and $3.507 \AA$ at TS1-4n, and 2.040 and $3.692 \AA$ at TS1-4x. At the $\mathrm{ZW}$ intermediates the length of the N1-C4 single bond is $1.530 \AA$ (ZW-4n) and $1.518 \AA$ (ZW-4x), while the distance between the $\mathrm{C} 2$ and $\mathrm{C} 3$ atoms remains at 3.111 $\AA$ (ZW-4n) and $3.167 \AA$ (ZW-4x). Remarkably, at ZW-4n and ZW-4x, the ketene and the imine frameworks are not completely perpendicular; at these intermediates the $\mathrm{N} 1-\mathrm{C} 4-\mathrm{C} 3-\mathrm{C} 2$ dihedral angle is -75.6 degrees at $\mathbf{Z W - 4 n}$ and -79.1 degrees at $\mathbf{Z W - 4 x}$. This slight twist enables the approach of the $\mathrm{C} 3$ carbon of the ketene framework towards the $\mathrm{C} 2$ carbon of the imine one, thus favouring the
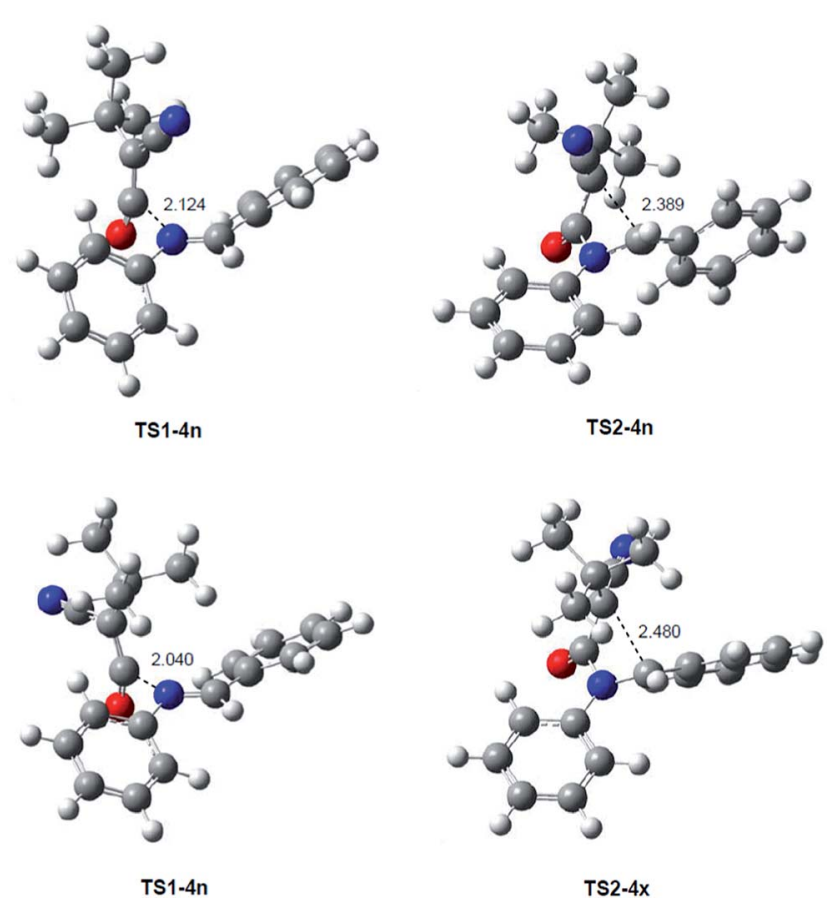

Fig. 2 MPWB1K/6-311G(d) geometries, in benzene, of the TSs associated with the $\mathrm{KI}-\mathrm{S}$ reaction between TBCK 11 and $\mathrm{N}$-phenyl imine $12 \mathrm{a}$. 
subsequent cyclisation process. ${ }^{15}$ At the TSs associated with the formation of the $\beta$-lactams, the length of the $\mathrm{C} 2-\mathrm{C} 3$ bond is $2.389 \AA$ at TS2-4n and 2.480 A at TS2-4x, while the length of the N1-C4 single bond has decreased to $1.439 \AA$ at TS2-4n and 1.430 A at TS2-4x.

The polar nature of this KI-S reaction was analysed by computing the global electron density transfer (GEDT). The natural atomic charges at the TSs and intermediates for the endo/exo channels, obtained through a natural population analysis (NPA), were shared between the ketene and the imine frameworks. In benzene, the GEDT that fluxes from the imine framework to the ketene one is $0.20 \mathrm{e}$ at TS1-4n, 0.55e at $\mathbf{Z W - 4 n}$ and $0.29 \mathrm{e}$ at TS2-4n along the endo approach mode, and $0.23 \mathrm{e}$ at TS1-4x, 0.55e at ZW-4x and 0.30e at TS2-4x along the exo one. These values indicate that along this stepwise reaction there is an increase of the GEDT along the nucleophilic attack of $N$-phenyl imine 12a on ketene 11, reaching the maximum value with the formation of the N1-C4 single bond at the corresponding ZW intermediates. The very high GEDT found at these intermediates points to their high $\mathrm{ZW}$ character and their great stability, in clear agreement with the high electrophilic character of TBCK 11, $\omega=1.36 \mathrm{eV}$, and the high nucleophilic character of $N$-phenyl imine 12a, $N=3.36 \mathrm{eV}$. From these ZW intermediates to the $\beta$-lactams there is a GEDT decrease as a consequence of a retro-donation along the ring-closure process.

\section{(ii) Origin of the cis/trans selectivity in the KI-S reaction}

As commented in the introduction, the KI-S reaction of unsymmetrically substituted ketenes and imines may form cis

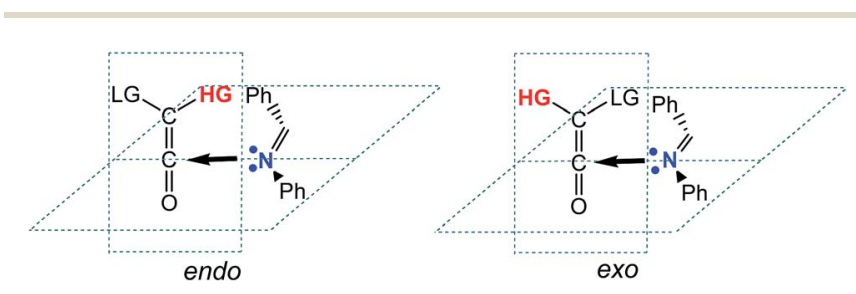

Scheme 8 Endo and exo stereoisomeric approach modes of the group of higher importance (HG) over the imine nitrogen atom. The LG group corresponds to the group of lower importance. and trans $\beta$-lactams (see Scheme 2). The unsymmetric substitution in ketenes, as in CCK 7 and TBCK 11, opens up the feasibility of two reactive channels along the approach of the imine nitrogen atom towards the central carbon atom of the ketene. Taking the group of higher importance of the ketene (HG) as reference, these approach modes can be named endo and exo (see Scheme 8).

The substituents present in the ketene can be classified as electron-withdrawing (EW) substituents able to increase the electrophilic character of the ketene, herein named type I, and bulky hydrocarbon substituents, herein named type II. Along the nucleophilic attack of the imine on the ketene, substituents type I can electronically interact with the imine nitrogen atom favouring the endo approach mode, while the unfavourable steric hindrance generated by a bulky hydrocarbon substituent type II favours the exo approach mode. In the case of disubstituted ketenes such as TBCK 11 the CN substituent type I prefers the endo approach mode, while the bulky $t$-butyl substituent type II prefers the exo one.

In order to analyse the effects of the ketene substitution in the endo/exo stereoselectivity along the KI-S reaction, the two stereoisomeric reaction channels associated with the nucleophilic attack of $N$-phenyl imine 12a on the monosubstituted ketenes 15a-c were studied (see Scheme 9). The relative energies of the stationary points associated with these KI-S reactions in benzene are given in Table 2, while the total electronic energies are given in Table S6 in the ESI. $\dagger$

When the ketene substituent is type $I, \mathrm{R}=\mathrm{CN}$, endo TS1-5an is located $1.5 \mathrm{kcal} \mathrm{mol}^{-1}$ below exo TS1-5ax. This low energy difference indicates that electronic factors have a low effect on the endo/exo stereoselectivity along the first step of the KI-S reactions. However, when the ketene substituent is type II, a bulky $t$-butyl group, a considerable effect on the stereoselectivity is observed; note that endo TS1-5cn is located $6.8 \mathrm{kcal} \mathrm{mol}^{-1}$ above exo TS1-5cx. Finally, for the small methyl group, endo TS1-5bn is located only $0.20 \mathrm{kcal} \mathrm{mol}^{-1}$ above exo TS1-5bx. Consequently, steric hindrances along the endo approach mode have a stronger effect on the stereoselectivity than electronic factors.

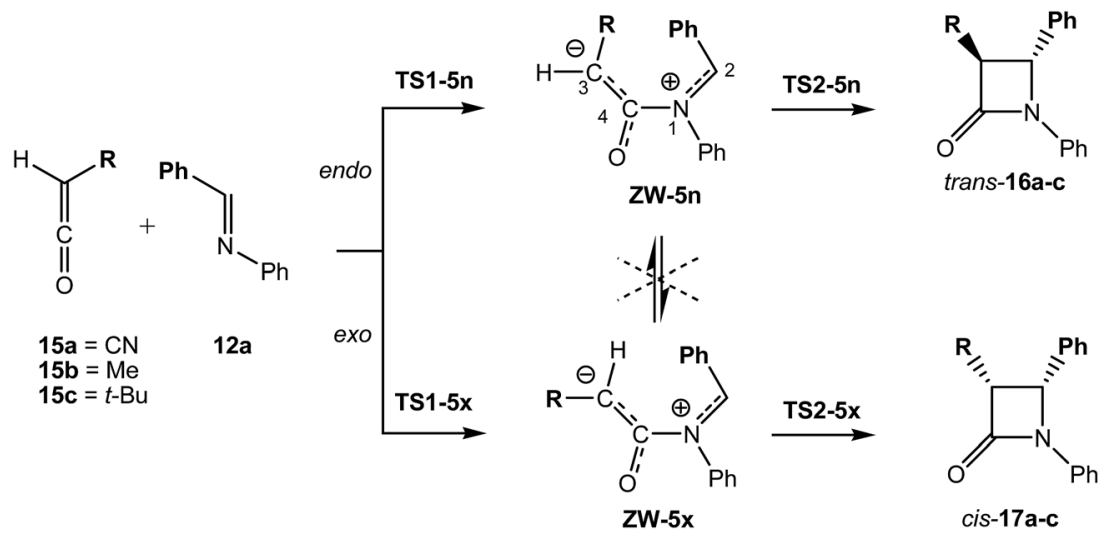

Scheme 9 Mechanism of the KI-S reaction between ketenes 15a-b and $\mathrm{N}$-phenyl imine 12a. 
Table 2 MPWB1K/6-311G(d) relative energies (in $\mathrm{kcal} \mathrm{mol}^{-1}$ ) in benzene of the stationary points along the endo and exo stereoisomeric channels associated with the $\mathrm{KI}-\mathrm{S}$ reactions of $\mathrm{N}$-phenyl imine $12 \mathrm{a}$ with the monosubtituted ketenes $15 \mathrm{a}-\mathrm{c}$

\begin{tabular}{lrlrlr}
\hline CN & \multicolumn{1}{c}{$\Delta E$} & Me & \multicolumn{1}{c}{$\Delta E$} & $t$-Bu & \multicolumn{1}{c}{$\Delta E$} \\
\hline TS1-5an & -1.2 & TS1-5bn & 8.0 & TS1-5cn & 16.7 \\
TS1-5ax & 0.2 & TS1-5bx & 7.8 & TS1-5cx & 9.9 \\
ZW-5an & -6.5 & ZW-5bn & 8.0 & ZW-5cn & 14.4 \\
ZW-5ax & -4.6 & ZW-5bx & 6.3 & ZW-5cx & 8.0 \\
TS2-5an & 14.2 & TS2-5bn & 21.4 & TS2-5cn & 27.1 \\
TS2-5ax & 11.7 & TS2-5bx & 14.1 & TS2-5cx & 16.0 \\
trans-16a & -38.4 & trans-16b & -44.7 & trans-16c & -43.5 \\
cis-17a & -37.4 & cis-17b & -44.5 & cis-17c & -39.6 \\
& & & & &
\end{tabular}

Along the second step of the KI-S reaction, only steric effects seem to control the ring-closure process. Thus, substituents type II yield endo ring-closure activation energies being 5.6 (TS2-5bn) and 4.7 (TS2-5cn) $\mathrm{kcal} \mathrm{mol}^{-1}$ higher than the exo ones. Interestingly, for substituents type $I$ there is a selectivity change, i.e. the ring-closure along the exo channel is 4.4 (TS2-5ax) kcal $\mathrm{mol}^{-1}$ lower in energy than the endo one. Consequently, along the second step of the KI-S reaction, the exo approach mode of the bulkier substituent is the preferred one. When the energies of the TSs are referenced to the separated reagents, the exo approach mode is 2.5 (TS2-5ax) 7.3 (TS2-5bx) and 11.1 (TS2-5cx) kcal $\mathrm{mol}^{-1}$ more favourable than the endo one.

Analysis of the electronic and steric effects in the endo/exo stereoselectivity along the nucleophilic attack of imines to ketenes, and the subsequent ring-closure at the corresponding ZW intermediates permits to conclude that the steric hindrance provoked by bulky substituents may be the main factor controlling the cis/trans stereoselectivity of KI-S reactions under kinetic control.

This analysis of the endo/exo selectivity in the KI-S reactions is in agreement with the endo selectivity found in the experimental reaction of TBCK 11 with $N$-phenyl imine 12a, in which the endo TSs TS1-4n and TS2-4n are found ca. $10 \mathrm{kcal} \mathrm{mol}^{-1}$ below the exo ones (see Fig. 1). Note that along the most favourable endo reactive channel the bulky $t$-butyl group is placed in an exo disposition with respect to the imine nitrogen atom.

The geometries of the most favourable exo TSs associated with the ring-closure step of the KI-S reaction of $N$-phenyl imine 12a with the monosubstituted ketenes 15a,c are given in Fig. 3. The geometries of TS2-5ax and TS2-5cx resemble those of the corresponding exo ZW intermediates. In both TSs, the ketene framework is slightly twisted in order to approach the $\mathrm{C} 2$ and the C3 carbons, while the $N$-phenyl imine framework remains almost unchanged. Therefore, neither conrotatory/disrotatory nor inward or outward movements take place along the ringclosure process, as has been proposed. ${ }^{4}$

The N1-C2 and C3-C4 bond order (BO) values at the most favourable zwitterionic intermediates are: 1.59 and 1.43 at ZW-5an, 1.61 and 1.61 at ZW-5bx, and 1.61 and 1.61 at ZW-5cx; these values suggest that these bonds have a high double bond character (see later). This behaviour is a consequence of the fact
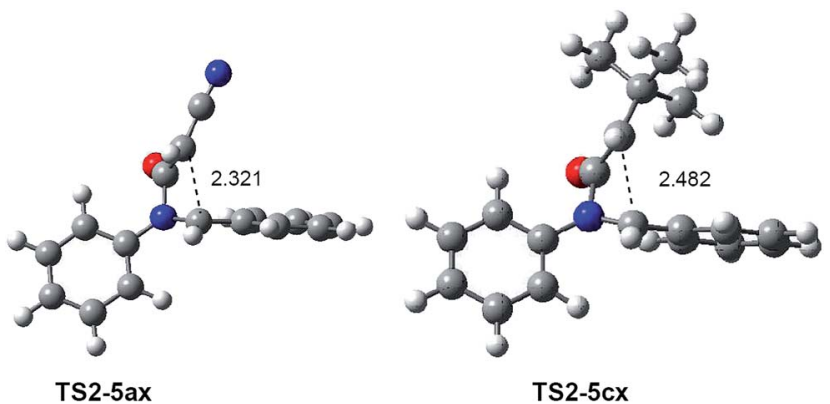

Fig. 3 MPWB1K $/ 6-311 \mathrm{G}(\mathrm{d})$ geometries of the most favourable exo TSs associated with the ring-closure step of the $\mathrm{KI}-\mathrm{S}$ reactions of $\mathrm{N}$-phenyl imine $12 \mathrm{a}$ with the monosubstituted ketenes $15 \mathrm{a}, \mathrm{c}$.

that along the nucleophilic attack of the N1 nitrogen atom on the $\mathrm{C} 4$ carbon atom of the ketene, the two N1-C2 and C3-C4 double bonds do not participate directly in the process (see later). These high $\mathrm{BO}$ values together with the high activation energy estimated for the $\mathrm{N} 1-\mathrm{C} 2$ and $\mathrm{C} 3-\mathrm{C} 4$ bond rotations at ZW-5an, higher than ca. $34 \mathrm{kcal} \mathrm{mol}^{-1}$, indicate that along these KI-S reactions neither $E / Z$ nor cis/trans isomerisations are feasible.

Consequently, trans $\beta$-lactams are obtained along the endo stereoisomeric channels, while cis $\beta$-lactams are obtained along the exo ones. Summing up, it can be concluded that the cis/trans stereoselectivity of the KI-S reaction is kinetically controlled by steric factors along the $\mathrm{C}-\mathrm{C}$ bond formation in the ring-closure step.

For the KI-S reaction between TBCK 11 and imine 12a in benzene, the present theoretical study permits to conclude that $\beta$-lactam trans-13a is the kinetic product, but Moore suggested by means of a H-NMR structural analysis that $\beta$-lactam cis-14a is the experimentally obtained product. ${ }^{18}$ The present theoretical study also indicates that experimental $\beta$-lactam cis-14a should be formed via TS2-4x, in which the bulky $t$-butyl group is endo with respect to the imine framework, a very unfavourable rearrangement being in clear agreement with the high energy of TS2-4x with respect to TS2-4n, ca. $8 \mathrm{kcal} \mathrm{mol}^{-1}$. On the other hand, $\beta$-lactam cis-14a could come from $(Z)-\mathbf{Z W}-\mathbf{3 a}$ as Moore proposed (see Scheme 6). ${ }^{18}$ However, the high energy associated with the $E / Z$ isomerisation allows ruling out the formation of ZW intermediate (Z)-ZW-3a. $\beta$-lactam cis-14a is found ca. 4 kcal $\mathrm{mol}^{-1}$ thermodynamically more stable than $\beta$-lactam trans-13a. Analysis of the Gibbs free energy profile of the KI-S reaction between TBCK 11 and imine 12a indicates that a thermodynamic control of the reaction is possible, favouring the formation of the experimental $\beta$-lactam cis-14a. These results suggest that the analysis of the cis/trans stereoselectivity in a KI-S reaction may be far more complex than a simple kinetic study.

\section{(iii) ELF topological analysis of the KI-S reaction}

A great deal of work has emphasised that the ELF topological analysis along a reaction path is a valuable tool to understand the bonding changes along the reaction path, and thus to characterise the molecular mechanism. ${ }^{8}$ After an analysis of the electron density, ELF provides basins which are the domains in 
which the probability of finding an electron pair is maximal. ${ }^{31}$ The basins are classified as core and valence basins. The latter are characterised by the synaptic order, i.e. the number of atomic valence shells in which they participate. ${ }^{32}$ Thus, there are monosynaptic, disynaptic, trisynaptic basins and so on. Monosynaptic basins, labelled V(A), correspond to lone pairs or non-bonding regions, while disynaptic basins, labelled V(A,B), connect the core of two nuclei A and B and, thus, correspond to a bonding region between $\mathrm{A}$ and $\mathrm{B}$. This description recovers the Lewis bonding model, providing a very suggestive graphical representation of the molecular system.

The ELF topological analysis along the cyclisation of the zwitterionic intermediate $\mathbf{Z W - 1 b}$ giving $\beta$-lactam trans-9b allowed establishing that formation of the $\mathrm{C}-\mathrm{C}$ bonds takes place through a retro-donation process involving the nucleophilically activated $\mathrm{C}-\mathrm{C}$ double bond of the ketene and the electrophilically activated $\mathrm{C}-\mathrm{N}$ double bond of the unsaturated imine (see Scheme 4). ${ }^{15}$

In order to gain insight into the complete characterisation of the molecular mechanism of the KI-S reaction, an ELF topological analysis of the bonding changes along the two reaction paths associated with the stepwise mechanism of the KI-S reaction between MCK 18 and $N$-methyl imine 19, yielding $\beta$-lactam trans-20, was performed (see Scheme 10). In this KI-S reaction the bulky $t$-butyl group present in TBCK 11 has been replaced by a methyl group in $\mathbf{1 8}$, and the $N$-phenyl substituent present in imine 12a has been replaced by a methyl group in 19. From an ELF topological view, neither group substitution alters any obtained conclusion. The gas phase energies of the stationary points involved in this stepwise reaction are given in Table S7 in the ESI. $\dagger$ In addition, an ELF topological analysis of the stationary points involved in the endo stereoisomeric path of the KI-S reaction between TBCK 11 and $N$-phenyl imine 12a is also performed. Details of these ELF topological analyses are also given in the ESI. $\uparrow$ The attractor positions of the ELF for the most relevant points associated with the $\mathrm{N} 1-\mathrm{C} 4$ and $\mathrm{C} 2-\mathrm{C} 3$ bond formation along the two-step KI-S reaction between MCK 18 and $N$-methyl imine 19 are given in Fig. 4, while the basin population changes along the two steps of this KI-S reaction are graphically represented in Fig. 5 .

Some appealing conclusions can be drawn from the ELF topological analysis of the KI-S reaction between MCK 18 and $N$-methyl imine 19: (i) along step I, only four differentiated phases associated with the formation of the N1-C4 single bond are observed (see Fig. 5); (ii) formation of the N1-C4 single bond takes place in the last Phase $I V$, at ca. $1.67 \AA$, by sharing the electron density of the imine $\mathrm{N} 1$ lone pair with the ketene $\mathrm{C} 4$ carbon (see the $\mathrm{V}(\mathrm{N} 1, \mathrm{C} 4)$ disynaptic basin, integrating $2.15 \mathrm{e}$, in
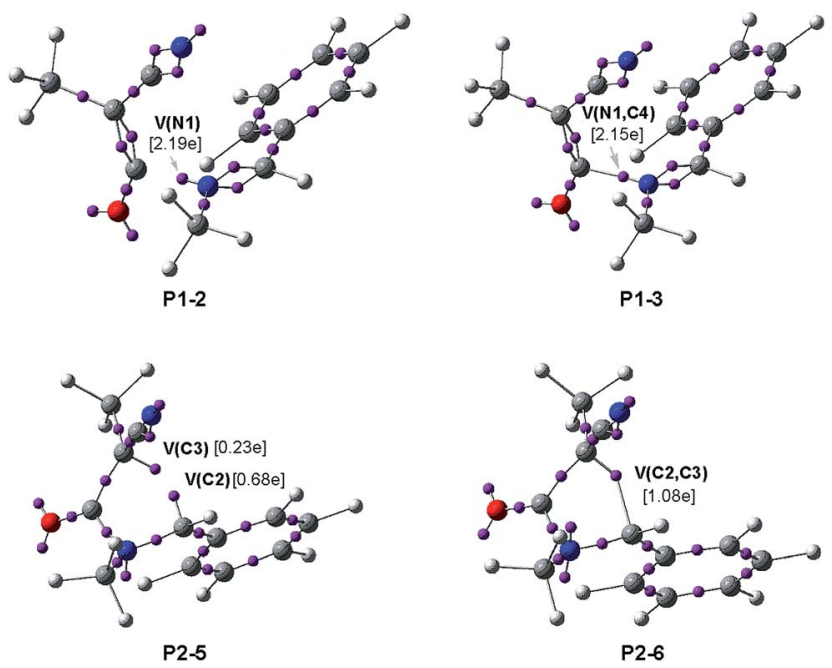

Fig. 4 ELF attractor positions of the most relevant points associated with the $\mathrm{N} 1-\mathrm{C} 4$ and $\mathrm{C} 2-\mathrm{C} 3$ bond formation along the two-steps $\mathrm{KI}-\mathrm{S}$ reaction between $\mathrm{MCK} 18$ and $\mathrm{N}$-methyl imine 19 . The electron populations, in e, are given in brackets.

structure P1-3 in Fig. 4, and the change from $\mathrm{V}(\mathrm{N} 1)$, in red in P1-2, to V(N1,C4), in blue in P1-3, in Fig. 5); (iii) along this step, while the $\mathrm{N} 1-\mathrm{C} 2$ and $\mathrm{C} 3-\mathrm{C} 4$ double bond regions remain characterised by the presence of two pairs of disynaptic basins, the $\mathrm{C} 4-\mathrm{O} 5$ bonding region of MCK 18 is depopulated in order to permit the N1-C4 single bond formation; (iv) along the nucleophilic attack of $N$-methyl imine 19 on MCK 18, there is a GEDT increase until reaching a maximum value with the complete formation of N1-C4 at ZW intermediate ZW-6n, 0.54e; (v) at ZW intermediate $\mathbf{Z W}-\mathbf{6 n}$, the $\mathrm{N} 1-\mathrm{C} 2$ and $\mathrm{C} 3-\mathrm{C} 4$ bonding regions are characterised by the presence of two disynaptic basins in each region (see ZW-6n in Fig. 5). This behaviour accounts for the high activation energy associated with the N1-C2, $44.6 \mathrm{kcal}$ $\mathrm{mol}^{-1}$, and $\mathrm{C} 3-\mathrm{C} 4,39.1 \mathrm{kcal} \mathrm{mol}^{-1}$, bond rotations, which prevent $E / Z$ imine and cis/trans ketene isomerisations. Note that these high rotational energies are similar to those found for the rotation of the $\mathrm{N} 1-\mathrm{C} 2$ and $\mathrm{C} 3-\mathrm{C} 4$ bonds at endo $\mathbf{Z W}-\mathbf{4 n}$; (vi) along step II seven phases are observed (see Fig. 5); (vii) in Phase II and Phase III, only bonding changes in the C3-C4 and N1-C2 regions take place in order to create the monosynaptic basin $\mathrm{V}(\mathrm{C} 2)$ in Phase $V$ and the monosynaptic basin V(C3) in Phase VI, which are demanded for the formation of the second C2-C3 single bond; ${ }^{33}$ (viii) in Phase IV a new V(N1) monosynaptic basin appears, which reaches a maximum population in Phase VI. The electron density of this basin comes from the depopulation of the $\mathrm{V}(\mathrm{N} 1, \mathrm{C} 2)$ disynaptic basin. These changes are associated
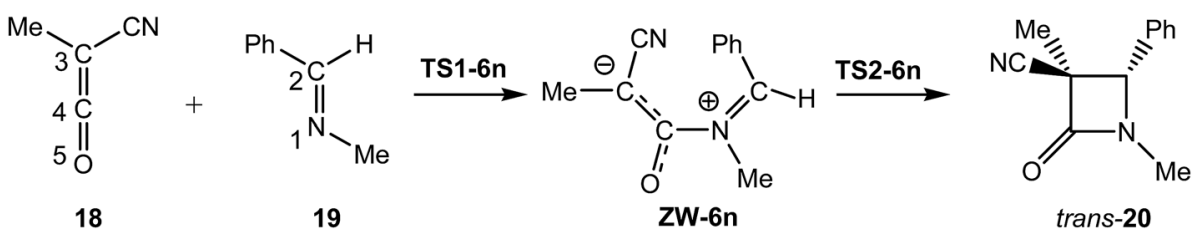

Scheme 10 Mechanism of the KI-S reaction between MCK 18 and N-methyl imine 19 


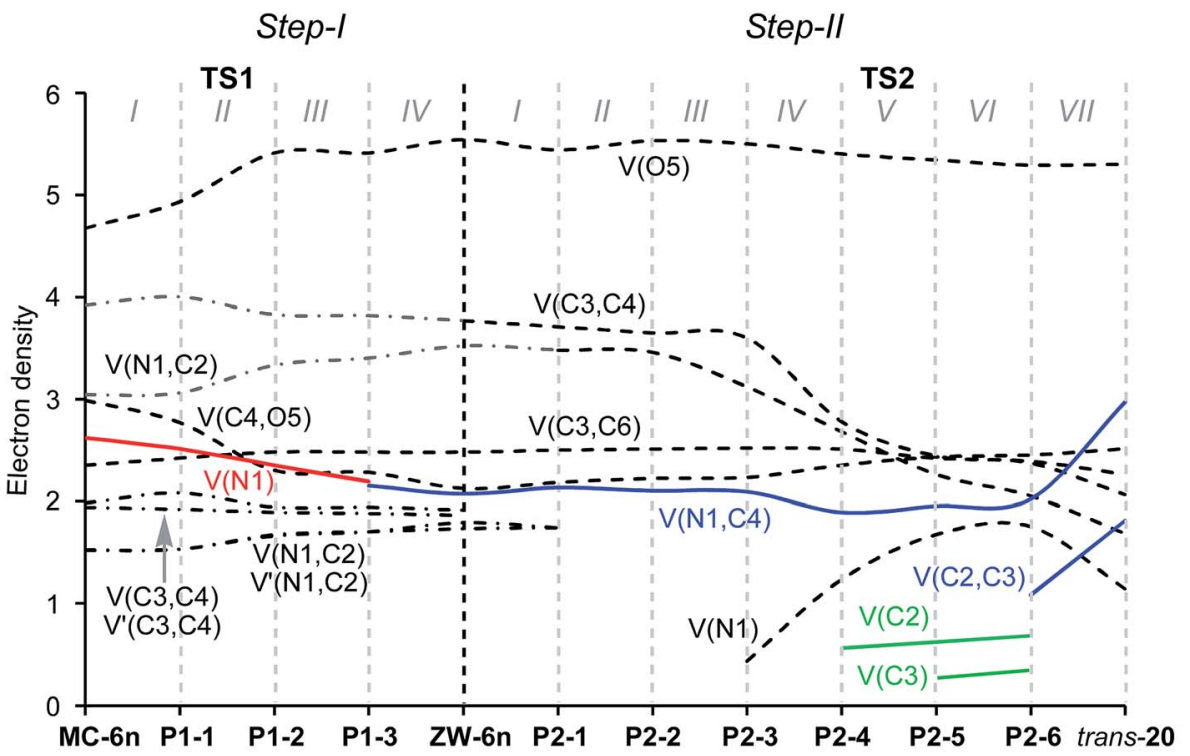

Selected points of the IRC defining the topological phases associated with the bonding-changes

Fig. 5 Graphical representation of the basin-population changes along the two-step KI-S reaction between MCK 18 and N-methyl imine 19 . Point-dotted curves in grey represent the sum of the $\mathrm{V}\left(\mathrm{C}_{x}, \mathrm{Cy}\right)$ and $\mathrm{V}^{\prime}(\mathrm{C} x, \mathrm{Cy})$ disynaptic basins describing a $\mathrm{C}-\mathrm{C}$ double bond region.

with the formation of the new $\mathrm{V}(\mathrm{C} 2)$ monosynaptic basin in Phase V; (ix) formation of the $\mathrm{C} 2-\mathrm{C} 3$ single bond takes place at Phase VII, at a C2-C3 length of $2.079 \AA$, through the C-to-C coupling of the $\mathrm{C} 2$ and $\mathrm{C} 3$ pseudoradical centers generated in the previous phases (see the $\mathrm{V}(\mathrm{C} 2)$ and $\mathrm{V}(\mathrm{C} 3)$ monosynaptic basins, integrating $0.68 \mathrm{e}$ and $0.23 \mathrm{e}$, respectively, in structure P2-5 and the $\mathrm{V}(\mathrm{C} 2, \mathrm{C} 3)$ disynaptic basin, integrating 1.08e, in structure P2-6 in Fig. 4); ${ }^{33}$ (x) along step II, the GEDT decreases as a consequence of a retro-donation process associated with the formation of the $\mathrm{C} 2-\mathrm{C} 3$ single bond; (xi) along the ringclosure step, no specific $\mathrm{N} 1-\mathrm{C} 2$ and $\mathrm{C} 3-\mathrm{C} 4$ bond rotation takes place along the $\mathrm{C} 2-\mathrm{C} 3$ bond formation; and finally, (xii) a comparison of the ELF of the stationary points involved in the KI-S reaction between TBCK 11 and imine 12a, and those involved in the reaction between MCK 18 and $N$-methyl imine 19 shows only small changes in the integration of the basins as a consequence of the different substitution in both reagents.

\section{Conclusions}

The mechanism of the KI-S reaction of TBCK 11 with $N$-phenyl imine 12a, yielding $\beta$-lactams trans-13a and/or cis-14a has been studied using DFT methods at the MPWB1K/6-311G(d) level. This KI-S reaction takes place through a two-step mechanism: (i) the first step is the nucleophilic attack of the imine nitrogen lone pair on the central carbon of the ketene yielding a ZW intermediate; (ii) the second step is a ring-closure process achieved by the nucleophilic attack of the terminal carbon atom of the ketene on the imine carbon atom.

Along the first step, the imine molecule approaches the ketene in an almost perpendicular fashion until forming the corresponding $\mathrm{ZW}$ intermediates. This behaviour causes the subsequent ring-closure to take place through a slight movement in order to approach the two nucleophilic/electrophilic carbons of the ZW intermediate..$^{15}$ Consequently, neither a conrotaroty/disrotatory movement nor torquoelectronic effects along the ring-closure, as has been proposed, ${ }^{4}$ take place. In addition, due to the double bond character of the imine $\mathrm{C}=\mathrm{N}$ and ketene $\mathrm{C}=\mathrm{C}$ bonds at the $\mathrm{ZW}$ intermediates, neither $E / Z$ imine nor cis/trans ketene isomerisations are feasible.

Analysis of the Gibbs free energy profile of the reaction between TBCK 11 and $N$-phenyl imine 12a indicates that the second step is the rate- and stereoselectivity-determining step of the KI-S reaction. Due to the unfeasibility of the $E / Z$ imine and cis/trans ketene stereoisomerisation at the $\mathrm{ZW}$ intermediates, formation of trans and/or cis $\beta$-lactams depends on the relative Gibbs free energies of the endo/exo TSs associated with the ringclosure process, and not on the endo/exo approach mode along the first step of the reaction. This analysis indicates that while $\beta$-lactam trans-13a is the kinetic control product, the experimental $\beta$-lactam cis-14a should proceed from a thermodynamic control.

Analysis of the endo/exo stereoselectivity along the KI-S reaction of three monosubstituted ketenes, $\mathrm{NC}-$, Me- and $t-\mathrm{Bu}$, indicates that steric hindrances are the main factor controlling the endo/exo stereoselectivity at the second reaction step and, consequently, the kinetic formation of cis/trans $\beta$-lactams.

An ELF quantum topological analysis of the bonding changes along the reaction between MCK 18 with $N$-methyl imine 19 permits a complete characterisation of the mechanism of the KI-S reaction. The first step is topologically very simple. Formation of the $\mathrm{N}-\mathrm{C}$ single bond takes place in the last Phase III, at $c a$. $1.67 \AA$, by sharing the electron density of the imine nitrogen lone pair with the ketene central carbon. Along this step, while the imine $\mathrm{N}-\mathrm{C}$ and ketene $\mathrm{C}-\mathrm{C}$ double bond regions 
remain topologically characterised by the presence of two pairs of disynaptic basins, the ketene $\mathrm{C}-\mathrm{O}$ bonding region of MCK 18 is depopulated in order to permit the $\mathrm{N}-\mathrm{C}$ single bond formation. Along the first step there is a GEDT increase until reaching a maximum value with the formation of the corresponding $\mathrm{ZW}$ intermediate, $0.54 \mathrm{e}$.

At the $\mathrm{ZW}$ intermediate, the imine $\mathrm{N}-\mathrm{C}$ and ketene $\mathrm{C}-\mathrm{C}$ bonding regions are characterised by the presence of two disynaptic basins in each region. This behaviour accounts for the high activation energy associated with the imine $\mathrm{N}-\mathrm{C}$ and ketene $\mathrm{C}-\mathrm{C}$ bond rotations, which prevent the $E / Z$ imine and cis/ trans ketene isomerisations.

Along the ring-closure step, formation of the new $\mathrm{C}-\mathrm{C}$ single bond takes place at a C-C length of $2.079 \AA$, through the C-to-C coupling of two pseudoradical centers generated in previous phases. ${ }^{33}$ Along this step, no specific imine $\mathrm{N}-\mathrm{C}$ and ketene $\mathrm{C}-\mathrm{C}$ bond rotations take place along the formation of the second $\mathrm{C}-\mathrm{C}$ single bond, ruling out any torquoelectronic effect. ${ }^{4}$ In addition, ELF population analysis of the $\mathrm{N}-\mathrm{C}$ single bond formed along the first step of the reaction indicates that it does not participate in the ring-closure process. This behaviour, which is contrary to that observed in the electrocyclic aperture of cyclobutene $\mathbf{5},{ }^{8 b}$ makes it possible to reject any electrocyclic process along the second step of KI-S reactions. ${ }^{4}$

The present theoretical study together with the recent study devoted to the selectivity in the formation of $\beta$ - $v s$. $\delta$-lactams in KI-S reactions using unsaturated imines ${ }^{15}$ allows us to reject these theoretical studies based on the FMO theory, in which HOMO/LUMO interactions along the nucleophilic attack of the imines on the ketenes and torquoelectronic effects along a conrotatory pseudo-electrocyclic reaction control the cis/trans stereoselectivity in the formation of $\beta$-lactams.

\section{Acknowledgements}

This work has been supported by the Ministerio de Economía y Competitividad of the Spanish Government, project CTQ201345646-P. M. R.-G. thanks the Ministerio de Economía y Competitividad for a pre-doctoral contract (BES-2014-068258).

\section{References}

1 (a) R. Southgate and S. Elson, The Chemistry of Organic Natural Products, Springer-Verlag, Wien, 1985, vol. 47; (b) R. Southgate, C. Branch, S. Coulton and E. Hunt, Recent Progress in the Chemical Synthesis of Antibiotics and Related Microbial Products, Springer-Verlag, Berlin, 1993, vol. 2; (c) R. Southgate, Contemp. Org. Synth., 1994, 1, 417.

2 (a) H. Staudinger, Justus Liebigs Ann. Chem., 1907, 356, 51; (b) T. T. Tidwell, Ketenes, John Wiley \& Sons, New York, 1995.

3 (a) The Organic Chemistry of $\beta$-Lactams, ed. G. I. Georg, Verlag Chemie, New York, 1993; (b) C. Palomo, J. M. Aizpurua, I. Ganboa and M. Oiarbide, Eur. J. Org. Chem., 1999, 3223; (c) G. S. Singh, Tetrahedron, 2003, 59, 7631; (d) C. Palomo, J. M. Aizpurua, I. Ganboa and M. Oiarbide, Curr. Med. Chem., 2004, 11, 1837; (e) B. Alcaide, P. Almendros and
C. Aragoncillo, Chem. Rev., 2007, 107, 4437; (f) A. Brandi, S. Cicchi and F. M. Cordero, Chem. Rev., 2008, 108, 3988.

4 F. P. Cossío, A. Arrieta and M. A. Sierra, Acc. Chem. Res., 2008, 41, 925.

5 (a) J. A. Sordo, J. González and T. L. Sordo, J. Am. Chem. Soc., 1992, 114, 6249; (b) F. P. Cossío, J. M. Ugalde, X. López, B. Lecea and C. Palomo, J. Am. Chem. Soc., 1993, 115, 995; (c) F. P. Cossío, A. Arrieta, B. Lecea and J. M. Ugalde, J. Am. Chem. Soc., 1994, 116, 2085; (d) A. Arrieta, B. Lecea and F. P. Cossío, J. Org. Chem., 1998, 63, 5869; (e) A. Arrieta, F. P. Cossío, I. Fernández, M. Gómez-Gallego, B. Lecea, M. J. Mancheno and M. A. Sierra, J. Am. Chem. Soc., 2000, 122, 11509; (f) A. Venturini and J. González, J. Org. Chem., 2002, 67, 9089; (g) B. K. Banik, B. Lecea, A. Arrieta, A. de Cózar and F. P. Cossío, Angew. Chem., Int. Ed., 2007, 46, 3028; (h) I. Fernández, M. A. Sierra, M. J. Mancheno, M. Gómez-Gallego and F. P. Cossío, J. Am. Chem. Soc., 2008, 130, 13892.

6 (a) H. W. Moore and G. Hughes, Tetrahedron Lett., 1982, 23, 4003; (b) W. T. Brady and C. H. Shieh, J. Org. Chem., 1983, 48, 2499.

7 (a) W. Kirmse, N. G. Rondan and K. N. Houk, J. Am. Chem. Soc., 1984, 106, 7989; (b) C. W. Jefford, G. Bernardelli, Y. Wang, D. C. Spellmeyer, A. Buda and K. N. Houk, J. Am. Chem. Soc., 1992, 114, 1157.

8 (a) V. Polo, J. Andrés, S. Berski, L. R. Domingo and B. Silvi, J. Phys. Chem. A, 2008, 112, 7128; (b) J. Andrés, S. Berski, L. R. Domingo, V. Polo and B. Silvi, Curr. Org. Chem., 2011, 15, 3566; (c) J. Andrés, P. González-Navarrete and V. S. Safont, Int. J. Quantum Chem., 2014, 114, 1239.

9 A. D. Becke and K. E. Edgecombe, J. Chem. Phys., 1990, 92, 5397.

10 (a) A. Savin, A. D. Becke, J. Flad, R. Nesper, H. Preuss and H. G. Vonschnering, Angew. Chem., Int. Ed., 1991, 30, 409; (b) B. Silvi and A. Savin, Nature, 1994, 371, 683; (c) A. Savin, B. Silvi and F. Colonna, Can. J. Chem., 1996, 74, 1088; (d) A. Savin, R. Nesper, S. Wengert and T. F. Fassler, Angew. Chem., Int. Ed. Engl., 1997, 36, 1809.

11 K. Fukui, J. Phys. Chem., 1970, 74, 4161.

12 K. N. Houk, J. González and Y. Li, Acc. Chem. Res., 1995, 28, 81.

13 F. A. Carey and R. J. Sundberg, Advanced Organic Chemistry. Part A: Structure and Mechanisms, Springer, New York, 2000.

14 R. B. Woodward and R. Hoffmann, Angew. Chem., Int. Ed. Engl., 1969, 8, 781.

15 L. R. Domingo and J. A. Sáez, RSC Adv., 2014, 4, 58559.

16 R. G. Parr, L. Von Szentpaly and S. Liu, J. Am. Chem. Soc., 1999, 121, 1922.

17 (a) L. R. Domingo, E. Chamorro and P. Pérez, J. Org. Chem., 2008, 73, 4615; (b) L. R. Domingo and P. Pérez, Org. Biomol. Chem., 2011, 9, 7168.

18 H. W. Moore, G. Hughes, K. Srinivasachar, M. Fernandez, N. V. Nguyen, D. Schoon and A. Tranne, J. Org. Chem., 1985, 50, 4231.

19 Y. Zhao and D. G. Truhlar, J. Phys. Chem. A, 2004, 108, 6908. 20 W. J. Hehre, L. Radom, P. v. R. Schleyer and J. A. Pople, $A b$ initio Molecular Orbital Theory, Wiley, New York, 1986. 
21 (a) H. B. Schlegel, J. Comput. Chem., 1982, 3, 214; (b) Modern Electronic Structure Theory, ed. H. B. Schlegel and D. R. Yarkony, World Scientific Publishing, Singapore, 1994.

22 (a) C. González and H. B. Schlegel, J. Phys. Chem., 1990, 94, 5523; (b) C. González and H. B. Schlegel, J. Chem. Phys., 1991, 95, 5853.

23 (a) J. Tomasi and M. Persico, Chem. Rev., 1994, 94, 2027; (b) B. Y. Simkin and I. Sheikhet, Quantum Chemical and Statistical Theory of Solutions - Computational Approach, Ellis Horwood, London, 1995.

24 (a) E. Cances, B. Mennucci and J. Tomasi, J. Chem. Phys., 1997, 107, 3032; (b) M. Cossi, V. Barone, R. Cammi and J. Tomasi, Chem. Phys. Lett., 1996, 255, 327; (c) V. Barone, M. Cossi and J. Tomasi, J. Comput. Chem., 1998, 19, 404.
25 (a) A. E. Reed, R. B. Weinstock and F. Weinhold, J. Chem. Phys., 1985, 83, 735; (b) A. E. Reed, L. A. Curtiss and F. Weinhold, Chem. Rev., 1988, 88, 899.

26 S. Noury, X. Krokidis, F. Fuster and B. Silvi, Comput. Chem., 1999, 23, 597.

27 M. J. Frisch, et al., Gaussian 09, Revision A.02, Gaussian Inc, Wallingford CT, 2009.

28 (a) R. G. Parr and R. G. Pearson, J. Am. Chem. Soc., 1983, 105, 7512; (b) R. G. Parr and W. Yang, Density Functional Theory of Atoms and Molecules, Oxford University Press, New York, 1989.

29 W. Kohn and L. J. Sham, Phys. Rev., 1965, 140, 1133.

30 Y. Zhao and D. G. Truhlar, Theor. Chem. Acc., 2008, 120, 215.

31 A. Savin, J. Chem. Sci., 2005, 117, 473.

32 B. Silvi, J. Mol. Struct., 2002, 614, 3.

33 L. R. Domingo, RSC Adv., 2014, 4, 32415. 